\title{
Directional Growth of Tin Crystals Controlled by Combined Solute Concentration Gradient Field and Static Magnetic Field
}

\author{
Lei Li $\cdot$ Bo Xu $\cdot$ Wei-Ping Tong $\cdot$ Hui Zhang $\cdot$ Chun-Yan Ban $\cdot$ Li-Zi He $\cdot$ Zhi-Hao Zhao $\cdot$ Yu-Bo Zuo $\cdot$ \\ Qing-Feng Zhu $\cdot$ Jian-Zhong Cui
}

Received: 24 July 2014/Revised: 1 December 2014/Published online: 19 March 2015

(C) The Chinese Society for Metals and Springer-Verlag Berlin Heidelberg 2015

\begin{abstract}
A new method was introduced to achieve directional growth of Sn crystals. Microstructures in liquid $(\mathrm{Pb}) /$ liquid (Sn) diffusion couples were investigated under various static magnetic fields. Results show that the $\beta$-Sn crystals mainly reveal an irregular dendritic morphology without or with a relatively low static magnetic field $(\leq 0.3 \mathrm{~T})$. When the magnetic field is increased to $0.5 \mathrm{~T}$, the $\beta$-Sn dendrites close to the final stage of growth begin to show some directional character. With a further increase in the magnetic field to a higher level $(0.8-5 \mathrm{~T})$, the $\beta$-Sn dendrites have an enhanced directional growth character, but the dendrites show a certain deflection. As the magnetic field is increased to $12 \mathrm{~T}$, the directional growth of the $\beta$-Sn dendrites in the center of the couple is severely destroyed. The mechanism of the directional growth of the $\beta$-Sn crystals and the deflection of the $\beta$-Sn crystals with the application of static magnetic field was tentatively discussed.
\end{abstract}

KEY WORDS: Microstructural evolution; Crystallization behavior; Dendrite growth; Diffusion behavior; Magnetic field; Solidification pattern

\section{Introduction}

Directional solidification has been widely used for fundamental research due to its flexibility to control two independent parameters of pulling speed and temperature gradient. Based on this technique, some classic theories were proposed, such as constitutional supercooling criterion [1], Mullins-Sekerka interface stability criterion [2]

Available online at http://link.springer.com/journal/40195

L. Li ( $ه)$ - W.-P. Tong · H. Zhang · C.-Y. Ban · L.-Z. He ·

Z.-H. Zhao - Y.-B. Zuo - Q.-F. Zhu - J.-Z. Cui

Key Laboratory of Electromagnetic Processing of Materials, Ministry of Education, Northeastern University,

Shenyang 110819, China

e-mail: lilei@epm.neu.edu.cn

B. Xu

School of Metallurgy and Energy, Hebei United University,

Tangshan 063009, China and Jackson-Hunt model for eutectic solidification [3], which contributed greatly in the field of solidification science. Accompanying the proposition of these theories, many directional solidification methods were also developed, e.g., liquid metal cooling (LMC) [4], fluidized bed quenching (FBQ) [5], zone melting and liquid metal cooling (ZMLMC) [6], supercooling directional solidification (SDS) [7] and Ohno continuous casting (OCC) [8]. To achieve directional crystal growth, these methods are usually conditioned by one-dimensional heat flow, positive temperature gradient at the solid-liquid interface and prevention of convections in the liquid. To meet any of these conditions, complicated technology and installation are required. Therefore, it may be of significance if some new method for achieving directional crystal growth by simpler technology and installation can be developed.

The classical grain structure of a casting or ingot is represented by three distinct zones: the outer chill zone, the intermediate columnar zone and the central equiaxed zone [9]. In other words, it is difficult to obtain a pure 
directionally solidified structure in such a casting or ingot due to the multidirectional heat flow. However, assuming a continuous long-range concentration gradient field (LRCGF) in the melt, directional crystal growth could be achieved in an above-mentioned casting or ingot. For binary alloys, it is known that alloys with different compositions usually correspond to different liquidus temperatures. Due to the concentration gradient field, there will be a time lag in the crystallization of the local melt during the synchronous cooling process. As a consequence, the melt may crystallize successively to form directional structure.

To build the LRCGF, one of the methods is preparing a solid/liquid or liquid/liquid diffusion couple. As previously mentioned, avoidance of convection in the liquid is one of the essential conditions for directional solidification. To ensure directional growth of the crystals, this condition is also needed in the present work. However, it is known that natural convections exist in the liquid even without an external stirring, which have important influences on the solute redistribution. It is conceivable that the LRCGF should be sensitive to these convections. Therefore, some measures should be taken to weaken these convections. With the quick development of electromagnetic processing of materials, the imposition of a magnetic field during the solidification of metallic alloys has been a hot topic [1014]. A static magnetic field (SMF) can induce Lorentz force to weaken and even suppress the convections in the melt. Therefore, the application of a SMF to the diffusion couple should promote the growth of crystals in a stable and directional pattern. Moreover, the high SMF is also characterized by the capacity to modify the macro- and microstructures of the alloys during the solidification process due to the induced magnetization force (MF) and thermoelectric magnetic force (TEMF), which has also been widely demonstrated [15-21]. Hence, it is of great importance and potential interest to impose an external SMF to the diffusion couple during the solidification process. Up to now, to our knowledge, experiments based on such a conception have not been reported elsewhere.

In such a context, liquid $(\mathrm{Pb}) /$ liquid $(\mathrm{Sn})$ diffusion couples were prepared and treated under SMFs in this work. Some very original phenomena regarding directional growth of tin crystals controlled by the combined solute concentration gradient field and SMF were preliminarily and qualitatively investigated.

\section{Experimental}

$\mathrm{Pb} / \mathrm{Sn}$ diffusion couples were prepared as follows: Firstly, a $\mathrm{Pb}$ disk $(\phi 4 \mathrm{~mm} \times 3 \mathrm{~mm})$ and a $\mathrm{Sn}$ cylinder $(\phi$ $4 \mathrm{~mm} \times 10 \mathrm{~mm}$ ) were machined and polished, and then, the $\mathrm{Pb}$ disk was put into a tube of corundum crucible $(\phi$
$4 \mathrm{~mm} \times 50 \mathrm{~mm}$ ) and the Sn cylinder placed on the disk, as schematically shown in Fig. 1. Figure 2 shows the scheme of the experimental apparatus. The equipment consists of a vacuum resistance furnace installed in the bore of the magnet and a superconducting magnet that can produce an axial static magnetic field (along $z$ direction) with a maximum magnetic flux density of $12 \mathrm{~T}$ at the position $z=0$ (i.e., $B_{z=0}=12 \mathrm{~T}$ ), where the magnetic field can be regarded as relatively uniform within $\pm 20 \mathrm{~mm}$ (when $\left.B_{z=0}=12 \mathrm{~T}, B_{z= \pm 20}=11.8974 \mathrm{~T}\right)$. An R-type thermocouple is used to measure the furnace temperature (the temperature field in the furnace is relatively uniform within $\pm 75 \mathrm{~mm}\left(< \pm 5^{\circ} \mathrm{C}\right)$ in the axial direction). In the present work, each couple was fixed at the position $z=0$. After the magnetic filed reached the set value (low fields of 0.1, 0.3, 0.5 and $0.8 \mathrm{~T}$; high fields of $1,3,5$ and $12 \mathrm{~T}$ ), the couple was heated up to $350^{\circ} \mathrm{C}$ (the melting points of $\mathrm{Pb}$ and $\mathrm{Sn}$ are 327.5 and $231.9^{\circ} \mathrm{C}$, respectively $)$ in vacuum $\left(2 \times 10^{-3}\right.$ $\mathrm{Pa}$ ) by an electric heater at a rate of $5{ }^{\circ} \mathrm{C} / \mathrm{min}$ and held for $30 \mathrm{~min}$ to make it completely melted and then cooled to room temperature at a rate of $10{ }^{\circ} \mathrm{C} / \mathrm{min}$ (during the cooling process, the heat flow transferring from the inner crucible toward outside is not directional but in all directions). Additionally, to demonstrate the influence of solute concentration gradient on the directional growth of $\mathrm{Sn}$ crystal, two Sn-10 wt\% Pb cylinders having a uniform composition were also prepared and treated under the same conditions as above (without and with a 12-T SMF).

Thereafter, the specimens were cut lengthwise from the treated couples and then mechanically polished. The

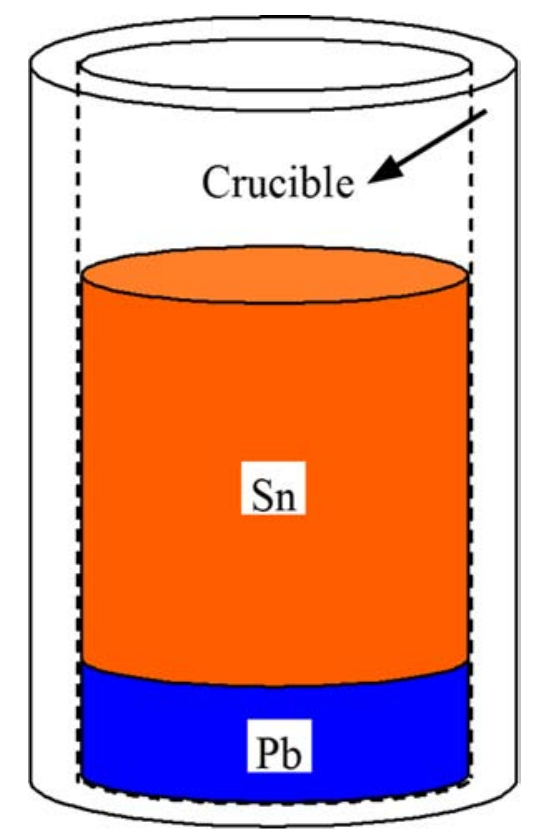

Fig. 1 Schematic diagram of $\mathrm{Pb} / \mathrm{Sn}$ diffusion couple preparation 


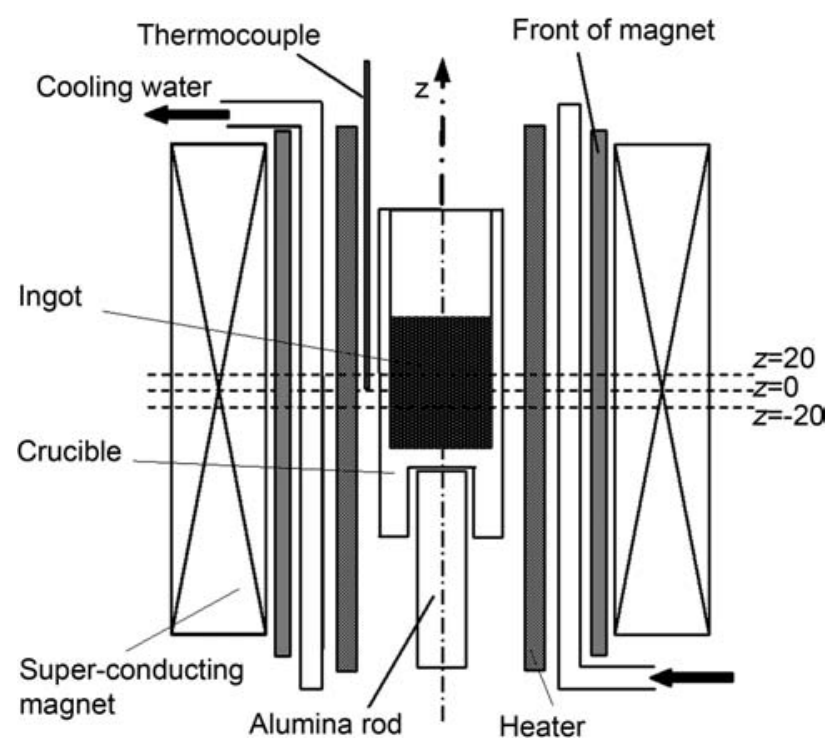

Fig. 2 Schematic diagram of the experimental apparatus

microstructures were observed by the Leica DMR microscope.

\section{Results and Discussion}

Figure 3a shows the microstructure of the $\mathrm{Sn}-10 \mathrm{wt} \% \mathrm{~Pb}$ specimen without SMF. It can be found that the primary $\beta$ Sn phase (lighter color) does not show a directional growth character but a uniformly distributed dendritic structure across the entire specimen longitudinal section. A microscopic observation on the $\mathrm{Sn}-10 \mathrm{wt} \% \mathrm{~Pb}$ specimen with a 12-T SMF indicates that the SMF has no obvious influence on such dendritic structure, which is therefore not shown herein.

Figure $3 b$ shows the microstructure of the Sn dendrites in the upper part of the liquid $(\mathrm{Pb}) /$ liquid $(\mathrm{Sn})$ couple without SMF. As it can be seen, the primary $\beta$-Sn phase in the hypereutectic structure He (above the dashed line) still shows an irregular dendritic morphology without a directional growth character. However, the structure is not uniform any more. From the top down, the distribution density of $\beta$-Sn phase decreases gradually. Moreover, a eutectic $\alpha-\mathrm{Pb}+\beta$-Sn region (below the dashed line) appears below the hypereutectic structure. A magnified eutectic structure is shown in Fig. 3c.

Figure 4 shows the microstructures of the center of the couples with low SMFs of 0.1, 0.3, 0.5 and $0.8 \mathrm{~T}$, respectively. As can be seen, with the 0.1- and 0.3-T SMFs, the $\beta$-Sn still does not display evident directional character. When the SMF is increased to $0.5 \mathrm{~T}$, for the $\beta$-Sn dendrites close to the final stage of growth, some directional character appears. When the SMF is further increased to $0.8 \mathrm{~T}$,

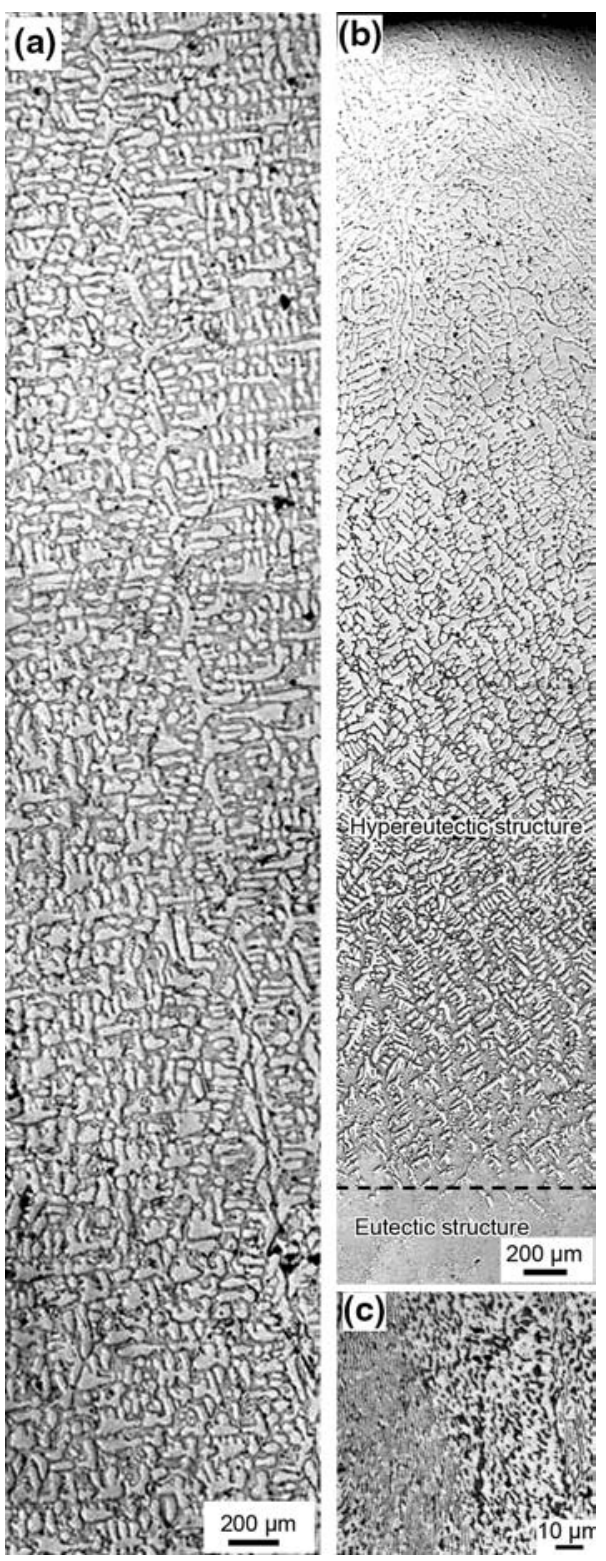

Fig. 3 a $\mathrm{OM}$ images of the microstructures of $\mathrm{Sn}-10 \mathrm{wt} \% \mathrm{~Pb}$ specimen; b $\mathrm{Sn}$ dendrites in the upper part of the liquid $(\mathrm{Pb}) /$ liquid (Sn) couple; $\mathbf{c}$ the magnified image of the eutectic region in $\mathbf{b}$

the directional growth character of the columnar $\beta$-Sn arrays is enhanced, but some of the arrays deflect from the axial direction.

Figure 5 shows the microstructures of the center of the couples with high SMFs of $1,3,5$ and $12 \mathrm{~T}$, respectively. It can be found that the $\beta$-Sn dendrites display enhanced directional growth character in the range of 1- to 5-T SMFs. However, the columnar dendrites show a certain deflection from the axial direction. When the SMF is further increased to $12 \mathrm{~T}$, the directional growth of the central $\beta$-Sn dendrites is severely destroyed.

Additionally, it can also be found that in each of the couple, both the primary and secondary dendrite arms of the directional $\beta$-Sn crystals decrease gradually in size from the initial 

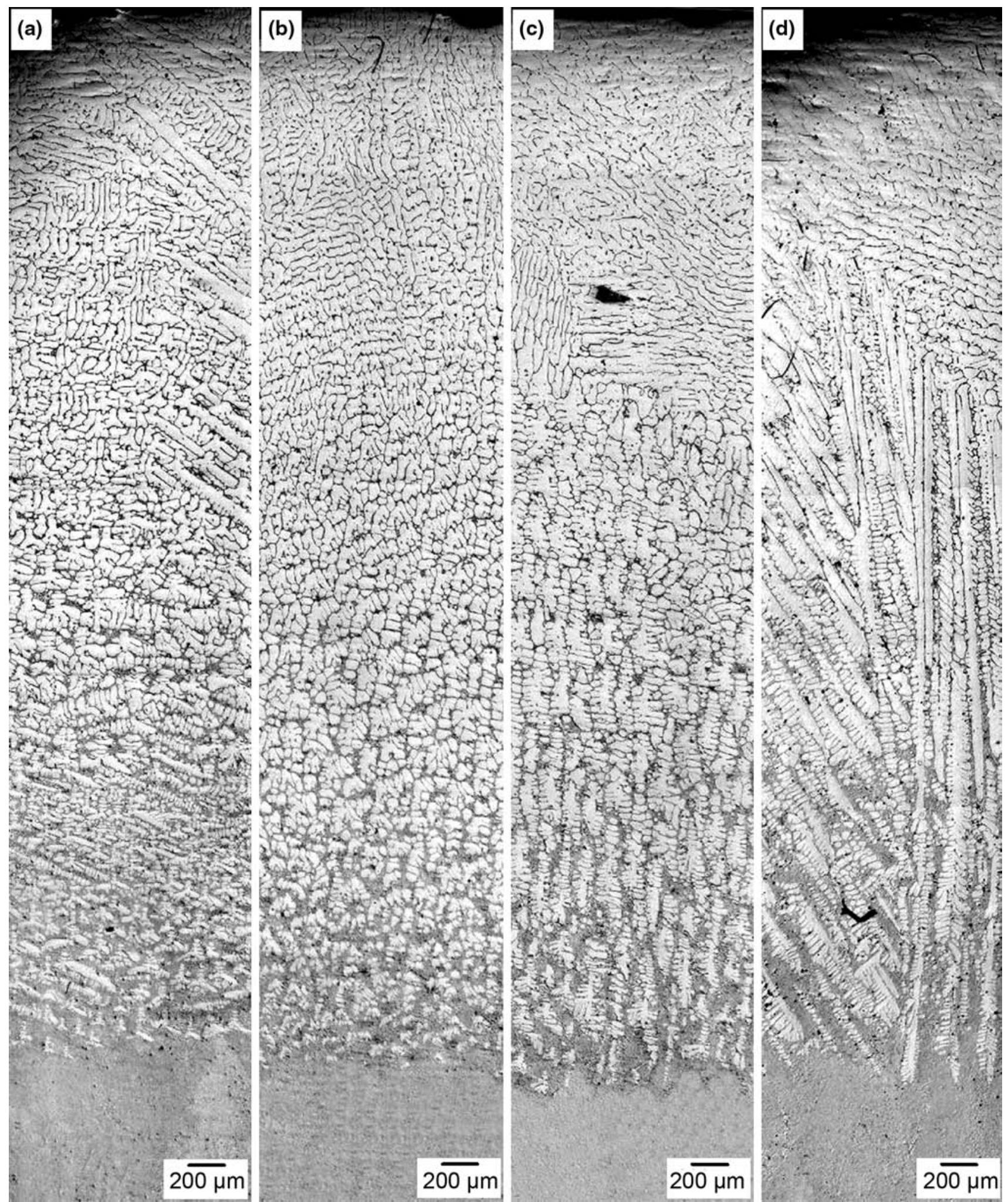

Fig. 4 Microstructures of the top $\mathrm{Sn}$ side of the $\mathrm{Pb}-\mathrm{Sn}$ couples which were solidified under $\mathrm{SMF}$ of $0.1 \mathrm{~T} \mathbf{a}, 0.3 \mathrm{~T} \mathbf{b}, 0.5 \mathrm{~T} \mathbf{c}$ and $0.8 \mathrm{~T} \mathbf{d}$

to the final growth stage (see Figs. $4 \mathrm{c}, \mathrm{d}$ and $5 \mathrm{a}-\mathrm{c}$ ). And in all the couples eutectic $\alpha-\mathrm{Pb}+\beta$-Sn regions are formed below the $\beta$-Sn dendrites and less affected by the SMF.
The experimental results above prove our previous conception that a LRCGF together with a sufficiently strong SMF can surely make the $\mathrm{Sn}$ crystals grow 


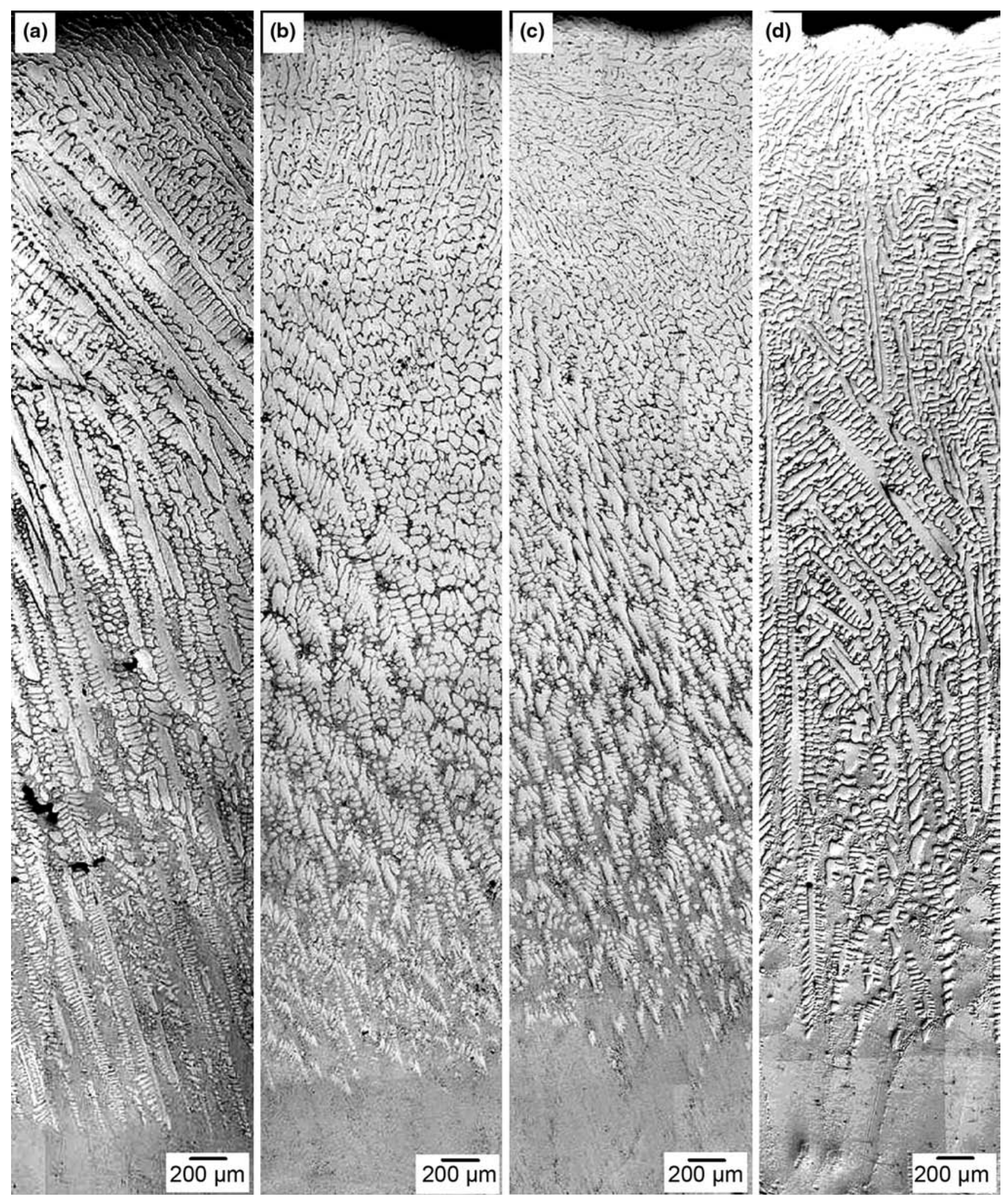

Fig. 5 Microstructures of the top $\mathrm{Sn}$ side of the $\mathrm{Pb}-\mathrm{Sn}$ couples which were solidified under $\mathrm{SMF}$ of $1 \mathrm{~T} \mathbf{a}, 3 \mathrm{~T} \mathbf{b}, 5 \mathrm{~T} \mathbf{c}$ and $12 \mathrm{~T} \mathbf{d}$

directionally, which is quite different from the conventional directional solidification technique. Simultaneously, the SMF also induces some other interesting phenomenon.
In this work, both the $\mathrm{Pb}$ and $\mathrm{Sn}$ in the couples are in liquid state at $350{ }^{\circ} \mathrm{C}$. In such case, an interdiffusion process occurs: The $\mathrm{Pb}$ atoms tend to enter into the $\mathrm{Sn}$ melt, while 
the $\mathrm{Sn}$ atoms to the $\mathrm{Pb}$ melt. To illustrate this process, Fig. 6a shows the schematic composition profiles of the $\mathrm{Pb}$ atoms in the whole melt (here it should be specially mentioned that these profiles are schematic and do not represent the real composition distribution in the melt), where the vertical axis denotes the height of the melt. During the mixing process, the $\mathrm{Pb}$ composition profiles change from the initial (1) to the final (5) with time, of which (5) represents an equilibrium state of the system. However, in the present work, the treating time $(30 \mathrm{~min})$ should not be sufficient enough to make the atoms distributed completely randomly. Thus, profiles (2)-(4) may represent the final composition distribution in the melt. If so, a LRCGF can be formed: The $\mathrm{Pb}$ concentration in the $\mathrm{Sn}$ melt decreases as the distance from the $\mathrm{Pb}$ melt increases. As an example, Fig. $6 \mathrm{~b}$ schematically shows a probable state of the composition distribution (corresponding to profile (4) in Fig. 6a).

Figure 7 shows the $\mathrm{Pb}-\mathrm{Sn}$ phase diagram [22]. It can be found that there is a eutectic reaction at composition of $61.9 \mathrm{wt} \% \mathrm{Sn}$. Due to the LRCGF, the Sn melt may cross eutectic and hypereutectic compositions, as shown in Fig. 6b. As previously mentioned in the introduction, alloys with different compositions have different liquidus temperatures. For $\mathrm{Pb}-\mathrm{Sn}$ alloy, the local $\mathrm{Sn}$ melt with a lower $\mathrm{Pb}$ composition will be crystallized firstly during the synchronous cooling process of the whole melt. For (a)

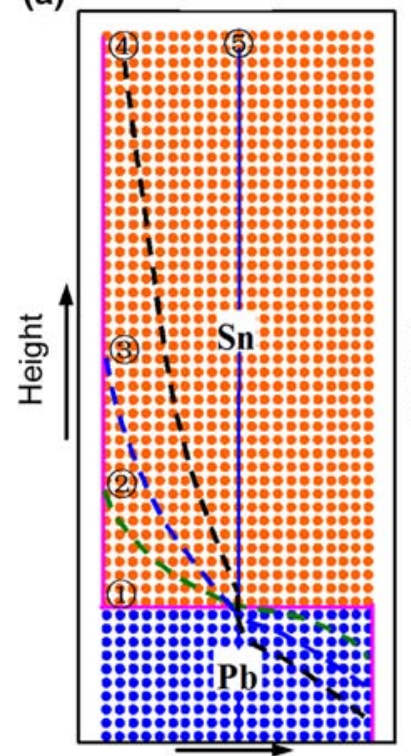

$\mathrm{Pb}$ content

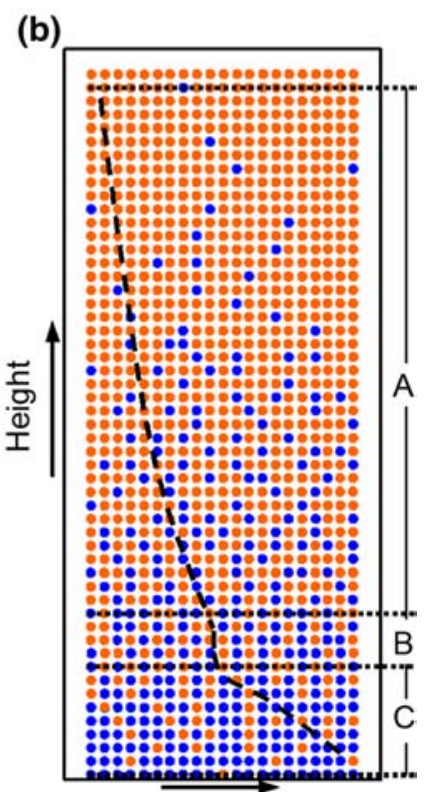

$\mathrm{Pb}$ content
Fig. 6 a Composition profiles of the $\mathrm{Pb}$ atoms changing from the initial (1) to the final (5) with time in the whole melt; $\mathbf{b ~} \mathrm{Pb}$ atoms distribution in the whole melt corresponding to a composition profile of (4) where $A, B$ and $C$ represent hypereutectic region, eutectic region and hypoeutectic region, respectively instance, as shown in Fig. 7, Sn-10 wt\% $\mathrm{Pb}$ (point A) has higher liquidus temperature than that of $\mathrm{Sn}-20 \mathrm{wt} \% \mathrm{~Pb}$ (point B), which means a prior crystallization of $\mathrm{Sn}-10$ $\mathrm{wt} \% \mathrm{~Pb}$ to that of $\mathrm{Sn}-20 \mathrm{wt} \% \mathrm{~Pb}$.

Figure 8a schematically shows the composition profile in the Sn melt, where the two vertical axes denote the heights of the $\mathrm{Sn}$ melt and the liquidus temperature, respectively. From Fig. 8a, it can be understood that the crystallization of the Sn melt should start from the top melt during the cooling process. To minimize the probable interfacial energy, its neighboring melt will not be nucleated independently but solidify and grow preferentially on the already crystallized $\beta$-Sn crystals, as schematically shown in Fig. 8b. In such a manner, the $\beta$-Sn crystals grow downwards continuously until the melt ahead of the solidification front reaches a eutectic composition, as schematically shown in Fig. 8c. Consequently, $\beta$-Sn crystals display a directional growth character. Based on this analysis, it can be known that such directional growth is the result of a time lag in the melt crystallization.

What discussed above is just an ideal situation. It has been mentioned that in reality, natural convections (such as buoyant, surface tension and thermo-capillary convections) exist in the liquid, which are usually irregular and unordered. When the mass transfer is dominated by such convections, the LRCGF will be disturbed and may even become discontinuous and random. The direct result is that the $\beta$-Sn crystals cannot grow directionally but form an irregular dendritic morphology (see Fig. 3b). When a SMF is applied, these convections tend to be suppressed due to the induced Lorentz force [23, 24]. Thus, the solute redistribution may be dominated by diffusion, which is favorable for the formation of a relatively continuous and

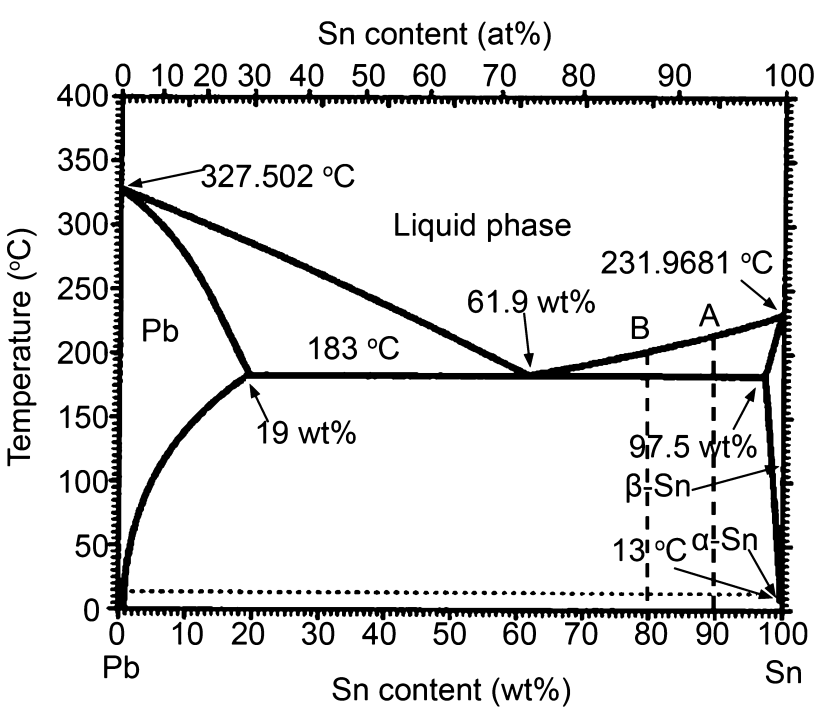

Fig. 7 Phase diagram of $\mathrm{Pb}-\mathrm{Sn}$ alloy [19] 
(a)

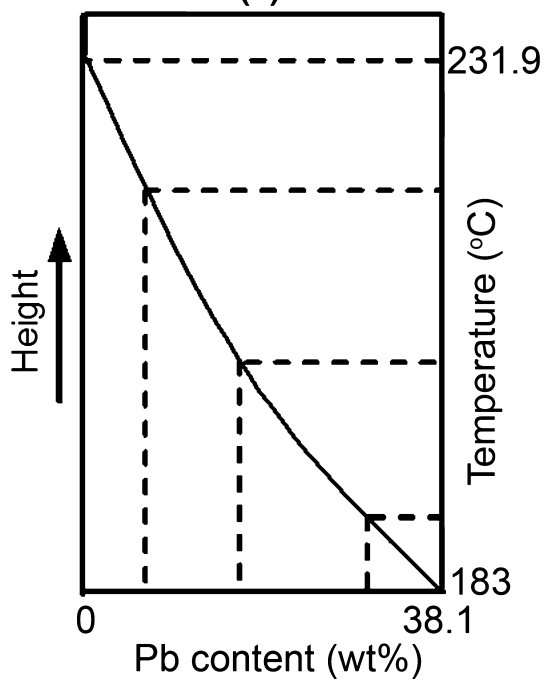

(b)

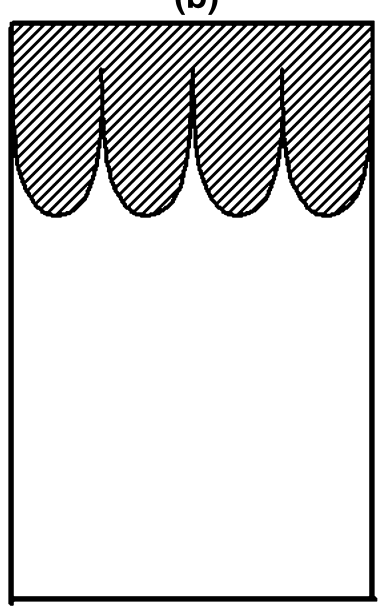

(c)

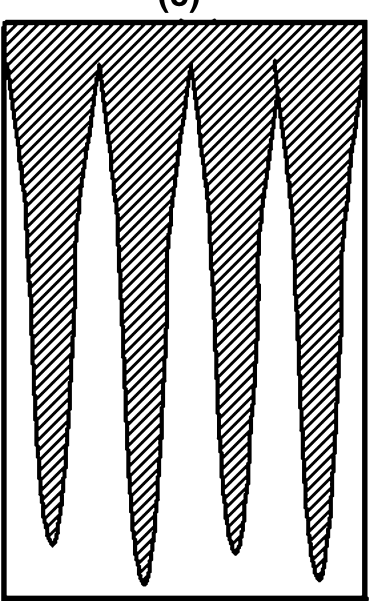

(d)

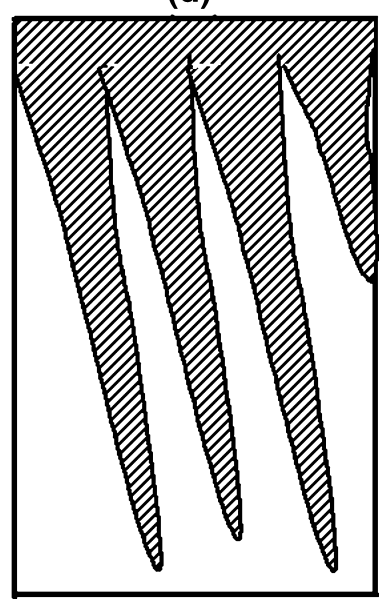

Fig. 8 a Composition profile in Sn melt; $\mathbf{b}$ schematic diagram of the crystallization starting from the top of Sn melt; $\mathbf{c}$ schematic diagram of $\beta$-Sn crystals growing downwards continuously; d schematic diagram of $\beta$-Sn crystals deflecting from the axial direction

regular LRCGF in the melt. However, a SMF of 0.1 or $0.3 \mathrm{~T}$ is not strong enough to suppress the natural convections effectively. As a consequence, the $\beta$-Sn crystals do not show an obvious directional character (Fig. 4a, b). With a further increase in the SMF to $0.5 \mathrm{~T}$, the suppression effect on the natural convections is enhanced. Therefore, some directional characters of the $\beta$-Sn dendrites appear (Fig. 4c).

When the SMFs are further increased to $0.8-5 \mathrm{~T}$, the suppression effect becomes stronger, thereby facilitating the directional growth of the $\beta$-Sn dendrites. However, under these increased SMFs, another type of convection, i.e., thermoelectric magnetic convection (TEMC), may be induced to affect the growth of the $\beta$-Sn dendrites [25]. On a large scale, the temperature field is relatively homogeneous during the melt solidification process in this work. However, it is almost impossible that the temperature gradients in local regions are absolute zero everywhere (e.g., the temperature in the central melt should be higher than that in the peripheral region in the present solidification way, and thus, a radial temperature gradient may exist). Thus, thermoelectric current in inter-dendritic liquid will be produced due to the Seebeck effects $[13,14]$. When SMF is imposed, Lorentz force driving the melt to flow will be induced. This flow is the so-called TEMC, which can also affect the crystal growth. It has been shown in other work that convections could result in a crystal growth deflection due to the concentration field change around a growing dendrite tip (crystal growth was suppressed in the solute-rich regions) [26]. However, the TEMC can also be suppressed by the SMF. Thus, a maximum flow velocity may exist when the TEMC is balanced with the suppression. In the present work, when the SMF reaches a certain value $(0.8-5 \mathrm{~T})$, the induced TEMC may be moderate and can lead to a regular asymmetric distribution of the solute around the dendrite tips and thus a certain deflection of the dendrites (Fig. 5a-c). However, when the SMF is further increased to $12 \mathrm{~T}$, as mentioned above, the TEMC may be enhanced to lead to a maximum flow velocity. This flow destroys the solute distribution around the dendrite tips and finally weakens the directional growth character. It may be expected that a further increase in the SMF (higher than $12 \mathrm{~T}$ ) could suppress the TEMC completely so that the $\beta$-Sn crystals could grow directionally and regularly again.

Moreover, from the $\mathrm{Pb}-\mathrm{Sn}$ phase diagram, it can be known that a higher $\mathrm{Pb}$ composition corresponds to a narrower temperature interval. At a certain cooling rate, it is natural that the $\beta$-Sn crystals crystallized from the melt with a higher $\mathrm{Pb}$ composition grow into smaller size. In the present work, due to the LRCGF, the Pb composition in the lower part of melt is higher than that in the upper part (here it is noteworthy that the $\mathrm{Pb}$ atoms rejected at the solidification front as the $\beta$-Sn dendrite tips proceed also contribute to the solute enrichment in the lower melt). Therefore, the distribution density of $\beta$-Sn phase decreases gradually from the top down in the couple without the magnetic field (Fig. 3b), and the primary and secondary dendrite arms of the directional $\beta$-Sn crystals become smaller gradually in size from the initial to the final growth stage (Figs. 4c, d and 5a-c).

In addition, hypoeutectic structure consisting of $\alpha-\mathrm{Pb}$ dendrites and eutectics were actually also formed below the eutectic region (see Fig. 6b). However, probably due to the 


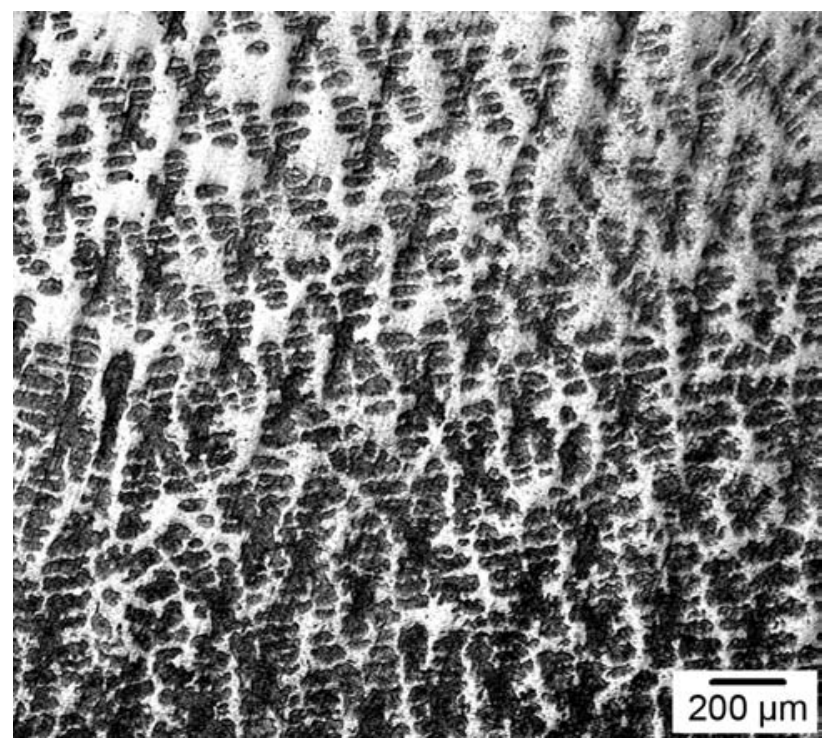

Fig. 9 Microstructure of $\mathrm{Pb}-\mathrm{Sn}$ alloy in the hypoeutectic region

short dimension of the $\mathrm{Pb}$ disk in the couple (i.e., no effective LRCGF is formed), most of the $\alpha$-Pb crystals show an irregular dendritic morphology even with a SMF, as shown in Fig. 9. Therefore, we do not plan to discuss such structure in this work.

Finally, it should be specially mentioned that the application of SMF does have a noticeable influence on the directional growth of the $\beta$-Sn crystals. However, despite of our effort to give a reasonable explanation, the mechanism induced by the SMF may be still far from the truth. Therefore, a further study is needed in the future.

\section{Conclusions}

1. Without or with a relatively low $\operatorname{SMF}(\leq 0.3 \mathrm{~T}), \beta$-Sn crystals mainly show an irregular dendritic morphology. When increase the SMF to $0.5 \mathrm{~T}$, the $\beta$-Sn crystals close to the final stage of growth begin to exhibit a directional growth character. As higher level of SMF $(0.8-5 \mathrm{~T})$ are employed, the directional growth character becomes more obvious, but the dendrites show a certain deflection. Using a 12-T SMF, the directional growth of the $\beta$-Sn dendrites in the center of the couple is severely destroyed.

2. Due to the atoms interdiffusion, a LRCGF is formed in the Sn melt. However, a continuous and regular LRCGF is facilitated by a sufficiently strong SMF that can effectively suppress natural convections in the melt. The directional growth of the $\beta$-Sn dendrites just arises from this LRCGF. The deflection of the $\beta$-Sn dendrites with the increase in the SMF is preliminarily attributed to the TEMC.

Acknowledgments This work was financially supported by the National Natural Science Foundation of China (Nos. 51201029, 51071042 and 51374067), the Fundamental Research Funds for the Central Universities (Nos. N130409002, N130209001 and N130709001), the China Postdoctoral Science Foundation (No. 2012M520637) and the National Basic Research Program of China (No. 2012CB619506).

\section{References}

[1] W.A. Tiller, K.A. Jackson, J.W. Rutter, B. Chalmers, Acta Metall. 1, 428 (1953)

[2] W.W. Mullins, R.F. Sekerka, J. Appl. Phys. 35, 444 (1964)

[3] K.A. Jackso, J.D. Hunt, Trans. Metall. Soc. AIME 236, 1129 (1966)

[4] A.F. Giamei, J.G. Tschinkel, Metall. Trans. A 7, 1427 (1976)

[5] Y.G. Nakagawa, K. Murakami, A. Ohtomo, Y. Saiga, ISIJ Trans. 20, 614 (1980)

[6] H.Z. Fu, X.G. Geng, Sci. Technol. Adv. Mater. 2, 197 (2001)

[7] F.Q. Xie, J.S. L, H.Z. Fu, Chin. Sci. Bull. 45, 131 (2000)

[8] Z.M. Zhang, T. Lu, C.J. Xu, X.F. Guo, Acta Metall. Sin. (Engl. Lett.) 21, 275 (2008)

[9] M.C. Flemings, Solidification Processing (McGraw-Hill, New York, 1974)

[10] T.J. Li, K. Sassa, S. Asai, Acta Metall. Sin. (Engl. Lett.) 10, 151 (1997)

[11] Y.B. Yu, Z.M. Ren, W.L. Ren, K. Deng, Y.B. Yun, Acta Metall. Sin. (Engl. Lett.) 22, 191 (1997)

[12] X.G. Zhang, Q. Zhao, J.S. Guo, Q.Y. Xing, L. Deng, X.G. Hou, C.F. Fang, Acta Metall. Sin. (Engl. Lett.) 26, 345 (2013)

[13] L. Li, Y.D. Zhang, C. Esling, Z.H. Zhao, Y.B. Zuo, H.T. Zhang, J.Z. Cui, J. Mater. Sci. 44, 1063 (2009)

[14] L. Li, Y.D. Zhang, C. Esling, Z.H. Zhao, Y.B. Zuo, H.T. Zhang, J.Z. Cui, J. Cryst. Growth 311, 3211 (2009)

[15] X. Li, Y. Fautrelle, Z.M. Ren, J. Cryst. Growth 306, 187 (2007)

[16] X. Li, Y. Fautrelle, Z.M. Ren, Acta Mater. 56, 3146 (2008)

[17] X. Li, Q.Y. Li, Z.M. Ren, Y. Fautrelle, X.G. Lu, A. Gagnoud, Y.D. Zhang, C. Esling, H. Wang, Y.M. Dai, Q.L. Wang, J. Alloys Compd. 581, 769 (2013)

[18] L. Li, Y.D. Zhang, C. Esling, H.X. Jiang, Z.H. Zhao, Y.B. Zuo, J.Z. Cui, J. Cryst. Growth 339, 61 (2012)

[19] L. Li, Y.D. Zhang, C. Esling, K. Qin, Z.H. Zhao, Y.B. Zuo, J.Z. Cui, J. Appl. Cryst. 46, 421 (2013)

[20] L. Li, Z.H. Zhao, Y.B. Zuo, Q.F. Zhu, J.Z. Cui, J. Mater. Res. 28, 1567 (2013)

[21] L. Li, Z.B. Li, Y.D. Zhang, C. Esling, H.T. Liu, Z.H. Zhao, Q.F. Zhu, Y.B. Zuo, J.Z. Cui, J. Appl. Cryst. 47, 606 (2014)

[22] K.J. Puttlitz, K.A. Stalter, Handbook of Lead-Free Solder Technology for Microelectronic Assemblies (Marcel Dekker Inc., New York, 2004)

[23] J.R. Carruthers, Preparation and Properties of Solid State Materials (Marcel Dekker, New York, 1997)

[24] D.H. Matthiesen, M.J. Wargo, S. Motakef, D.J. Carlson, J.S. Nakos, A.F. Witt, J. Cryst. Growth 85, 557 (1987)

[25] S.N. Tewari, R. Shah, S. Hui, Metall. Mater. Trans. A 25, 1535 (1994)

[26] M.C. Flemings, C.M. Adams, E.E. Hucke, H.F. Talor, Trans. AFS 64, 636 (1956) 